\title{
Network neutrality and the nature of competition between network operators
}

\author{
Viktória Kocsis • Paul W. J. de Bijl
}

Published online: 11 July 2007

(C) Springer-Verlag 2007

\begin{abstract}
The neutral architecture of the Internet is being challenged by various parties, such as network operators providing the connections to end-users, who are interested in gaining control of the information exchanged over the Internet. What are the effects on competition and welfare of such practices? Currently, there exists very little economic theory on network neutrality. This paper provides a preliminary analysis of the type of economic modeling that can address network neutrality, as well as of the type of results that can be expected.
\end{abstract}

Keywords Network neutrality - Discriminating practices · Product differentiation · Imperfect competition $\cdot$ Regulation

\section{Introduction}

Users of the Internet benefit from a stream of continuously emerging innovations in applications and services. These innovations give rise to a need for faster and more precise data transmission, which require investments and innovations by network operators. Certain innovations, such as Quality of Service (QoS) and the labeling of individual data packets (packet shaping), help operators to raise the priority of a

This paper is a revised version of a report (while the authors were affiliated with TILEC, Tilburg University) commissioned by the Directorate General for Energy and Telecommunications (DGET), Ministry of Economic Affairs, The Netherlands. Only the authors are responsible for the contents of this paper and any errors it may contain.

V. Kocsis $(\bowtie) \cdot$ P. W. J. de Bijl

CPB Netherlands Bureau for Economic Policy Analysis, P.O. Box 80510, 2508 GM,

The Hague, The Netherlands

e-mail: V.Kocsis@cpb.nl

P. W. J. de Bijl

ENCORE Fellows Network and TILEC, Tilburg University, P.O. Box 90153,

5000 LE Tilburg, Netherlands

email: pauldebij1@cpb.nl 
certain data flow or limit the priority of another flow. Such technologies may support the provision of applications that are time-sensitive (e.g. voice), or that require highbandwidth (e.g. video) or a higher level of security (e.g. e-commerce).

The Internet as we currently know it is based on a simple network architecture ${ }^{1}$, which allows any computer to send packets to any other computer, while packets are not inspected by the networks. As a result, all packets are treated in the same way, and literally anyone is able to build, implement and introduce (possibly as commercial services) new Web applications, without having to ask any party, such as an ISP or network operator, for permission. Of course, users typically have to pay for connections to the Internet, and the price they pay may depend on speed or quality. Nevertheless, network operators do not act as selective gatekeepers, and service providers do not pay network operators or ISPs to get exclusive access to particular users. Thus, the Internet, as it is based on freedom of connection with any application or service, and to any party, can therefore be seen as a neutral communications medium; it is characterized by "network neutrality."2,3

The neutral architecture of the Internet is being challenged by various parties, such as network operators providing the connections to end-users, who are strongly interested in gaining control of the information exchanged over the Internet. Such control would give them the possibility, for instance, to charge different prices for different types of information carried over their networks, to differentiate between QoS for different applications, and to block certain applications from their networks. Potentially, the impact on competition and the value derived by consumers of such behavior may be very large.

To some extent, differentiation based on QoS has already been implemented within IP-based networks, and at some point it could become a successor of the current "best effort" routing practice. Under QoS and demand-based discrimination in case of congestion, packets are treated on a first-in/first-out basis; but if congestion occurs, packets with less value drop out first. Currently, however, the Internet exhibits excess capacity ${ }^{4}$; yet a packet might be dropped out from the data flow according to a network operator's preferences, leading to discrimination in the data transmission. This form of discrimination has led to a heated debate on "network neutrality," particularly in the USA. ${ }^{5}$ This debate is now gaining prominence in Europe as well. ${ }^{6}$

\footnotetext{
${ }^{1}$ Based on certain protocols (known as TCP and IP).

${ }^{2}$ This description is based on the weblog of Tim Berners-Lee, one of the inventors of the Web, 21 June 2006, http://dig.csail.mit.edu/breadcrumbs/taxonomy/term/23.

${ }^{3}$ See van der Berg (2006) for a very useful overview of network neutrality discussion (in Dutch).

${ }^{4}$ Prüfer and Jahn (2007).

${ }^{5}$ See e.g. US Senate Committee Hearing on network neutrality, 7 February 2006, http://commerce.senate. gov/hearings/witnesslist.cfm?id=1705; a debate between C. Yoo and T. Wu, May 2006, http://legalaffairs. org/webexclusive/debateclub_net-neutrality0506.msp; a discussion between S. Crawford and C. Yoo, February 2006, http://www.pbs.org/now/shows/222/net-rules.html; the Quello Communication Law and Policy Symposium on 6 April 2006: http://www.quello.msu.edu/2006/schedule.htm; FTC workshop on "Broadband Connectivity Competition Policy", 13-14 February 2007, http://www.ftc.gov/opp/workshops/ broadband/index.html.

${ }^{6}$ For example, CRN Workshop: "Net Neutrality—Battle for a New World Order or Much Ado About Nothing?," 11 December 2006, London, http://www.cambridge-mit.org/events/article/default.aspx? objid=8.
}

钐 Springer 
There does not exist a precise definition of network neutrality-the concept is largely based on the four "Internet Freedoms" formulated by Michael Powell, then chairman of the FCC, to conclude a discussion on the 1996 US Telecommunications $\mathrm{Act}^{7}$ : consumers should be able to have access to lawful Internet content, to run applications and services of their choice, to attach devices to their connection, and to receive transparent information regarding network operators. The general idea is that the Internet should be operated under non-discrimination and should protect interconnection and end-to-end connectivity. Thus, all packets transmitted over the network are treated the same way by the networks, including the traffic originating within the network operator. This approach was expressed in the latest proposal for amendment, voted out by the US House on 8 June $2006 .{ }^{8}$

The main questions in the debate on network neutrality relate to the private incentives and the social costs and benefits caused by active packet shaping: how is competition affected? How are consumer choice and consumers surplus affected? How are the incentives to invest and innovate - in networks as well as applications and services - affected? The first two questions are particularly relevant for short term, the latter one for long term welfare.

There are a few reasons that make the discussion more complicated: one can witness very fast technological development and also changes in the business models of Internet-based firms. At the moment nobody can predict how the next generation network will function, and according to participants in the discussion, the market should sort out the outcome. Besides, from the subscriber-based characteristics of telecommunications networks, a shift can be observed toward a model relying on tailor-made advertisements and thereby potentially rearranging the structure of revenues gained in the broadband market.

In the current debate on network neutrality, two main streams of reasoning can be distinguished. According to proponents of network neutrality, the Internet should remain a neutral network, and according to some, the notion of network neutrality should find its way into the law. ${ }^{9}$ They argue that without network neutrality, endusers will get less choice, because investments and innovations by developers of applications and services that run over the Internet will be stifled. According to this view, the currently witnessed success of the Internet is due to innovations at the "edges" of the network rather than in the "core." Here, the core refers to intelligence inside of the network, while the edges correspond to functionality that end-users can implement themselves. The Internet should remain a commodity in the form of a "stupid network," providing capacity, interconnectivity and speed. ${ }^{10}$ As a result, the separation between the transport and application layers will remain intact, allowing for complete freedom by independent parties to develop innovations that run over the Internet.

\footnotetext{
${ }^{7}$ Powell (2004). See http://en.wikipedia.org/wiki/Network_neutrality for an overview of definitions.

${ }^{8}$ See Markey (2006). A new, called Snowe-Dorgan amendment is currently waiting for US house vote: http://static.publicknowledge.org/pdf/ina-staff-draft-20060404.pdf.

${ }^{9}$ Proponents are e.g. Lessig (2006), Wu (2005), Frieden (2006), Crawford (2007), and Berners-Lee (2007).

10 The definition originates from David Isenberg's online post from 1997 at http://isen.com/stupid.html.
} 
Among the opponents of network neutrality, some are fundamentally opposed to network neutrality regulation, which they view as interfering by the government in the way firms wish to do business. Others claim that network operators must be able to introduce different pricing structures in order to allow them to recoup investments in networks. They argue that without the possibility to do so - that is, in the presence of price regulation - their incentives to invest and innovate will be undermined. ${ }^{11}$ According to the latter view, the future success of the Internet depends on innovations at the "core" of the network rather than at the "edges," because of the interdependence and complementary relationship between network and application. For the same reason, it is argued that a network operator has no incentives to discriminate unduly in the long term anyway, at least not if there are competing networks that end-users can choose from. The best a regulator can do is therefore to intensify competition at the level of infrastructure. Nevertheless, they agree that if consumers cannot choose between networks, antitrust authorities will ultimately punish anticompetitive behavior, so that it will not occur in the first place. Overall, a likely outcome of abandoning the neutral nature of the Internet is that the transport and application layers will become integrated, reducing the freedom of independent parties that use the Internet.

Regulatory authorities, such as Ofcom in the UK and FCC or FTC in the USA, and international organizations, like $\mathrm{OECD}^{12}$ have recently started to actively participate in the discussion. At present they share the view that regulatory intervention should remain minimal and limited to ex post intervention in case of anticompetitive practices. However intensifying competition and providing transparency for the benefit of consumers are still a few of the most important policy goals which can be supported by ex ante regulation.

Currently, there exists very little economic theory on network neutrality. In this paper, we provide an outline of the type of economic modeling that can address network neutrality, as well as of the type of results that can be expected. In our argument we mainly focus on access-tiering in the presence of facilities-based competition and horizontal differentiation, in which setup this practice has not been presented yet. In addition, this paper relates some basic economic arguments to a situation characterized by competition between a DSL network and a cable network. The latter characteristic is relevant since it is sometimes claimed that as long as consumers can choose between networks, they can always switch if they do not like operators initiatives to reduce network neutrality (we will come back to this claim in the body of the paper).

We rely on standard insights from the theory of industrial organization (Tirole 1988); the economics of network industries (Shy 2002); and research on the economics of sabotage in vertically integrated market (Mandy and Sappington 2004; Sappington and Weisman 2005). There exist some economics papers on network neutrality, for instance van Schewick (2007), Ford et al. (2006), and Hahn and Wallsten (2006), although they use little or no economic modeling.

The closest paper to our conclusions is written by van Schewick who argues that in a duopoly situation, network operators have incentives to discriminate, which

\footnotetext{
${ }^{11}$ Opponents include Litan and Singer (2007), Sidak (2006), Waverman (2006) and Yoo (2005).

${ }^{12}$ See e.g. CRN Workshop in footnote 6.

型 Springer
} 
leads to exclusion of applications and content providers and thus to lack of innovations in that level; she therefore recommends network neutrality regulation. On the other hand she claims the costs of regulation-the decreasing incentives to invest in networks - are outweighed by the benefits from application-level innovation. One of the main differences from our paper is relating to this point. By assessing network-level investment in a setup which distinguishes the effects of horizontal differentiation from rent capturing, our welfare analysis shows that overall welfare will not necessarily decrease: even in the presence of discriminatory practices long-term welfare can increase. Another difference is that van Schewick focuses mainly on mandating network neutrality via the law. We discuss, in addition, already existing policy tools which may be sufficiently effective.

Emphasizing more the impact of network operators on welfare, Ford et al. (2006) argue that network neutrality regulation discourages entry in the sense that it reduces horizontal product differentiation, which is important for profitability and also investments. However they point out that product differentiation is undesirable for short-term welfare since it increases prices and decreases consumers' choice.

Although Hahn and Wallsten (2006) stand for a rather "hands-off" approach, they agree with network neutrality proponents that exclusion may occur which will harm consumers, however they claim that net neutrality regulation which they consider as a type of price regulation, would also harm welfare. Besides they trust in the multisided nature of the market that is due to network effects: the more consumers are subscribed, the more versatile content will survive. As a result, network operators still have incentives to transfer a wide range of content. Instead of network neutrality regulation, they suggest that policy should focus on reducing entry barriers: eliminating restrictions of the use of spectrum on the one hand, and on the other hand not determining who is entitled to enter the market and how it can use the infrastructure. Nevertheless the government has to continue to play an important role in antitrust enforcement if the market performs in an anticompetitive way.

The structure of the paper is as follows. Section 2 introduces potential discriminatory practices and provides a short overview of the institutional background in the EU as it relates to network neutrality. Section 3 introduces the framework we will use to explore network neutrality from an economics viewpoint. Using this framework, the most relevant discriminating practices are then analyzed. Access-tiering receives special attention. Finally Section 4 contains some preliminary policy recommendations, and briefly comments on the situation in the Netherlands.

\section{Background}

This section provides some background information on network neutrality and the legal framework in the EU. For the sake of brevity, we will not discuss recent developments in the broadband market. ${ }^{13}$

\footnotetext{
${ }^{13}$ For a recent overview of developments in broadband, see de Bijl and Peitz (2006).
} 
2.1 Practices that violate network neutrality

The main types of behavior that violate network neutrality are the following:

1. Port blocking and quality degradation: Using new technologies, a network owner is able to block access to or deliberately degrade the quality of data transmission from a web site providing applications, services or content. In an extreme case both operators may block part of the Internet for some end-users. In practice port blocking has already occurred, particularly relating to voice over Internet protocol (VoIP) services. ${ }^{14}$

2. Access-tiering: A network operator may discriminate in a way that it gives bandwidth priority at a price independent from Internet access fees to application, service and content providers that are willing to pay for quality of services. Network operators may auction off or sell lanes to application and service providers in order to capture rents from their producer surplus.

In addition, due to its discriminating characteristic, "consumer-tiering" is sometimes viewed to violate network neutrality. A network operator may offer different types of access contracts, based on differences in speed and volume, and sell them at different prices according to consumers' willingness to pay. However, we view this practice as an example of price discrimination when a consumer decides which package to choose and pays according to her preferences, similar to, for instance, the availability of different types of contracts in mobile telephony. Therefore consumer-tiering does not seem to be controversial in the current debate on network neutrality.

\subsection{Institutional background}

It is beyond the scope of this paper to make recommendations on the optimal way of implementing network neutrality, but it is nevertheless worthwhile to point out some legal issues. In legal terms, on the basis of the EU regulatory framework for electronic communications, network neutrality could conceivably be implemented via different routes.

Firstly, in the European Union, the wholesale broadband access market falls under the significant market power (SMP) regime regulated in the Access Directive. ${ }^{15}$ It is not clear whether this market definition adequately covers the problem. If it were so, then operators with SMP on this market could face certain obligations (in principle to be taken from the list of Articles 9 to 13 of the Access Directive), including nondiscrimination and/or access at regulated prices. In any event, the cluster of issues grouped under "network neutrality" would have to be broken down into specific obligations for that purpose.

\footnotetext{
${ }^{14}$ For an example in the US context, see the decision in the Madison River case which passed in March 2005 at http://hraunfoss.fcc.gov/edocs_public/attachmatch/DA-05-543A2.pdf. A European example concerns the announcement by Vodafone Germany (July 2005) to block Skype services via its 3G network from July 2007, see e.g. http://www.ovum.com/go/content/c,57072.

15 "Directive 2002/19/EC of the European Parliament and of the Council of 7 March 2002 on access to, and interconnection of, electronic communications networks and associated facilities", Official Journal of the European Communities, L 108/7.
}

型 Springer 
Secondly, in the Access Directive in Article 4 and 5, interconnection and interoperability have been set as principles, however no other specific enforceable regulation for interconnection and interoperability exist. Interconnection is based on negotiation, and the outcome depends on the bargaining power between the participants. Some issues falling under "network neutrality" could perhaps be dealt with under this heading. However, the power of the national regulatory authorities (NRAs) is limited, and furthermore, the precise scope of application of these provisions remains controversial. From responses to the call for input of the Commission for the review of the regulatory framework ${ }^{16}$, it can be seen that for some interested parties (e.g. from the UK and The Netherlands), interoperability and end-to-end connectivity should continue to be objectives and be guaranteed which calls for reconsidering the role of NRAs. Moreover any regulation imposed should not impede further investments. Arguably, freedom of contract should be retained and regulatory intervention should be undertaken only in case of anticompetitive behavior, of course unless ex ante intervention is more efficient than ex post dealing it.

Thirdly, network neutrality could also be implemented via stand-alone legislative provisions. The current European regulatory framework is now under review and could perhaps be augmented with such specific provisions. This solution may be easier on the legal side, but a political agreement at Member State level is necessary to effect such a change. Note that including network neutrality via specific provisions would run against the grain of the current regulatory framework, which rather tries to address such issues via regulatory procedures using more general concepts, such as SMP. ${ }^{17}$

\section{A simple economic analysis of network neutrality}

\subsection{Starting point and assumptions}

The starting point for our analysis will be a hypothetical situation in which:

1. There is network neutrality (this corresponds to the Internet as we currently know it),

2. There is effective competition between a small number of network operators (this may depend on the presence of network neutrality, as we will later see).

To a certain extent, the situation in some European countries, for instance in The Netherlands, may (soon) correspond to this starting point. This country has the second largest broadband penetration in the world and also in the EU $(31.8 \%$ in December 2006), while both the incumbent telecoms operator (KPN) as well as a small number of regional cable monopolist with an overall nationwide coverage are

\footnotetext{
${ }^{16} \mathrm{See}$ at http://europa.eu.int/information_society/policy/ecomm/info_centre/documentation/public_consult/ review/index_en.htm.

${ }^{17}$ Larouche (2000) in Chapter 4.I.A.2 points out similar gaps in the competition law instancing the discussion already burst over intelligent versus stupid networks as they are described by Isenberg (1997).
} 
able to offer triple play bundles. ${ }^{18}$ Thus there is facilities-based competition. In addition, due to regulation of local loop unbundling, there are various entrants who use KPN's local networks for access to end-users to offer Internet access based on DSL (Digital Subscriber Line), ensuring intensive service-based competition. Other technologies, such as fiber to the home (FTTH) provided by municipalities and wireless networks (WiFi, WLL and UMTS) also exist in the Dutch market, but their coverage is limited compared to the previous ones. ${ }^{19}$

When we talk about network operators, we include companies with their own infrastructure (network owners) and Internet service providers (ISPs) that use this infrastructure. ${ }^{20}$ Besides there exists a market for applications and services that run on that infrastructure (see Fig. 1). We will refer to the first market as networks level and the second as applications (or services) level. Note that the latter includes "plain" broadband access as a service in itself. End-users are the users of applications and services and can be consumers and producers as well, both are paying fees for having Internet access.

By looking what happens if network neutrality is abandoned in various ways, we will consider what happens to the effectiveness of competition and to welfare.

To evaluate the emerging situations from a policy perspective, we follow the approach developed in Bennett et al. (2001). ${ }^{21}$ By using their framework one can analyze, in a consistent and systematical way, "future" policy issues related to certain market developments. By viewing certain developments as a course of events with a momentum of their own (e.g. technological developments events with certain aspects that are beyond the control of policy and regulatory instruments), one can think through the potential effects of policy within a well-defined context.

The framework is characterized by an economist's approach to reduce market failure in order to increase welfare. The underlying idea is that policy and regulation may be used, for instance, to move the market to a better efficiency state (that is, with higher static and dynamic efficiency), or to prevent the market from moving to an undesirable efficiency state (with low static and dynamic efficiency). This approach abstracts from considerations related to redistribution, politics, and social goals not directly linked to maximizing social surplus.

To keep the analysis brief, some shortcuts will be taken compared to the approach by Bennett et al. During the analysis we will judge market outcomes and policy interventions by the criteria of static and dynamic efficiency. Higher static efficiency arises from an improved allocation of inputs by using existing technologies, while higher dynamic efficiency comes from investments in process innovation in order to lower costs of service provision (in telecoms this is typically done by investing in new types of equipment and infrastructure) and product innovation to provide new

\footnotetext{
${ }^{18}$ Triple play: a bundle of voice service, TV and Internet access.

${ }^{19}$ See OECD Broadband Statistics, December 2006, accessible at http://www.oecd.org/sti/ict/broadband and OPTA Annual Report 2005, accessible at http://www.opta.nl.

${ }^{20}$ To simplify the analysis, we treat local loop unbundling and bitstream access on the same level as the network owners. In a more detailed analysis, one should distinguish between network operators and entrants who use unbundled access as a means to reach end-users.

${ }^{21}$ de Bijl (2004) contains an accessible summary, which is useful for readers who are unfamiliar with this approach.
} 


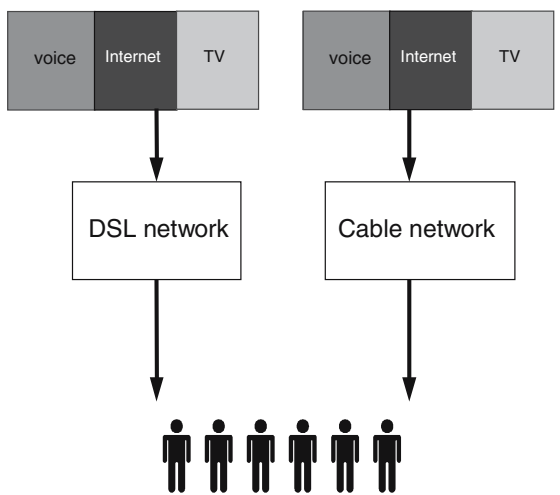

Applications level

application, service

and content providers

Networks level

network operators

End-users

Fig. 1 Illustration of market participants

and improved services (or higher speed) representing higher consumers value, both leading therefore to innovations that are welfare-increasing. All this is valid to the extent that such investments are not wasteful but lead to higher total surplus. Thus, static efficiency is a short-run welfare notion, and dynamic efficiency a long-run one. Outcomes that maximize dynamic efficiency at the expense of (short-run) efficiency generally outperform - in terms of the aggregate of per period welfare levels in the long run - the outcomes that maximize static efficiency at the expense of dynamic efficiency. Potential tradeoffs between static and dynamic efficiency may not be straightforward to assess, though. Consider for instance investments in additional networks. They may lead to more competition in quality of services (e.g. because of higher-speed networks that allow for additional functionality), but also to wasteful duplication.

To assess dynamic and static efficiency in a clear-cut setup, we will use three assumptions:

1. Application innovations at the edges are more important for dynamic efficiency than centralized innovations within networks.

2. Facilities-based competition at the networks level is characterized by a small number of networks, while more competition increases dynamic efficiency.

3. Network providers have incentives to horizontally differentiate their networks.

These assumptions are not purely hypothetical, as they are supported by empirical or theoretical considerations, which will be discuss below.

\subsubsection{Decentralized investments at the applications level}

It is important to make a distinction between on the one hand, innovation at the level of applications, content and services that run over the Internet, and on the other hand, the infrastructure. This distinction is relevant because of diverging incentives to invest. Upgrading network pipes is clearly focused on increasing speed, capacity, and reliability, so that the innovation process aiming at these goals can in a relatively straightforward way be organized within an organization with some level of central control. However, although one can organize applications innovation processes in a similar way, one would miss the wealth of information coming from experimentation and play by individuals and users who are not constrained by firm-specific goals. 
According to Odlyzko (2004), one of the misleading myths in the telecoms sector is that networks are able to develop innovative services. Although networks have been very innovative in improving their transport technologies, virtually all "killer applications" running over the networks have come from users of their networks and not from the carriers themselves. ${ }^{22}$ Odlyzko and also Berners-Lee (2007) argue that, because of convergence, the fraction of innovations coming from users at the edges of the networks will increase even further. In any case there is no reason to suspect that network operators can easily turn this into their core business, let alone at a level comparable of innovation generated through decentralized processes. ${ }^{23}$

Somewhat more generally, as one of the Internet's central features is user connectivity, it is this particular feature that will stimulate (decentralized) innovation more and more. This point is elaborated by von Hippel (2005), who discusses a wide variety of qualitative and empirical evidence behind the trend that new computer and communications technologies help users (both firms and individuals) to innovate by developing their own applications. ${ }^{24}$ The innovation processes benefit a lot from the increased ability to share information and knowledge among users. ${ }^{25}$ It is exactly this type of innovation-bottom-up, decentralized and fragmented, aided by the enormous communication power of the Internet - that generates the largest number of ideas, as it is users who do the experimentation and subsequent filtering of ideas themselves. In addition, we observe that not only the process, but often the application itself is becoming more and more decentralized: the connectivity of the Internet leads to a growing variety of peer-to-peer applications that run on end-users' PCs.

A final point worth mentioning is that small-scale, user-driven innovation may fulfill needs in the tiniest market niches ${ }^{26}$, since there is no tendency to aim at the largest common denominator among consumers. Overall, it seems safe to conclude that the gains for dynamic efficiency in applications and services, stemming from bottom-up processes among users, will be substantially larger, if not of a larger order of magnitude, than in the case of innovation that is centrally controlled.

\subsubsection{Small number of firms: investments at the networks level}

Another important point in the network neutrality discussion is whether the network owners have enough incentives to invest in their infrastructure. When we talk about investment at the networks level, we can mention on the one hand upgrading and maintenance of the existing networks, and on the other hand rolling out a new one.

\footnotetext{
${ }^{22}$ Let us also mention, that investments also take place in applications which have already existed in the market. For simplicity we will call them comparable services. These investments, mainly aimed at upgrading and maintenance, are generated by larger application providers and network operators.

${ }^{23}$ Of course there are situations in which centralized planning is superior to decentralized decisionmaking, but this is most likely not the case in situations with a lot of technological change and uncertainty. See $\mathrm{Wu}$ (2006), who discusses the relative efficiency of polyarchies and hierarchies as decision-making models.

${ }^{24}$ Benkler (2006) makes similar points in a broader setting when discussing peer production, sharing, and "social production."

${ }^{25} \mathrm{See} \mathrm{Wu}$ (2006) for more references on decentralized innovation processes.

${ }^{26}$ See Anderson (2004) and his notion of the "long tail."

型 Springer
} 
The first group of investments is carried out by wired telecommunications (in DSL technology) or cable companies, and the second group, newly emerging technologies such as WiFi, satellite, FTTX technologies (e.g. fiber to the home-FTTH, fiber to the building-FTTB or fiber to the node-FTTN) or power lines communications are being established by-beside the previously mention operators-wireless telecoms and satellite companies, municipalities or other utilities.

To assess the welfare relating to the networks level, potential tradeoffs between static and dynamic efficiency will be taken into account by adopting the "inverse U-shaped" relationship between the intensity of competition and dynamic efficiency (see Fig. 2, based on the work of Aghion et al. 2005). Generally, in case of a monopoly, the firm is not threatened by a competitive fringe potentially entering the market, therefore it has less incentive to invest and innovate. In case of cut-throat pricing competition, firms cannot gain supranormal profit - that is the revenue above variable costs - to invest or to recoup investments. In between these two extreme market situations there is a particular level of competition which leads to maximum dynamic efficiency.

In the broadband infrastructure market one can observed a certain level of facilities-based competition where the number of network operators owning their facilities is small, stands generally around two to four, depending on the incidence of alternative technologies. Although governments may have incentives to spur competition in order to support the spread of broadband penetration, the number of facilities-based companies will predictably not increase substantially due to the high entry costs and the economies of scale. Besides, empirical studies, for instance Wallsten (2006) and Distaso et al. (2006), show that interplatform competition has a strong impact on broadband adoption and also on investments at the networks level. So far the stronger the competition has been, the more the network owners invested in connection speed. Based on these facts we claim that current level of competition is located in the left-hand part of the inverse U-shaped curve that is with the increasing relationship between competition and long-term welfare effects. Later in the analysis we will refer only to this part of the curve.

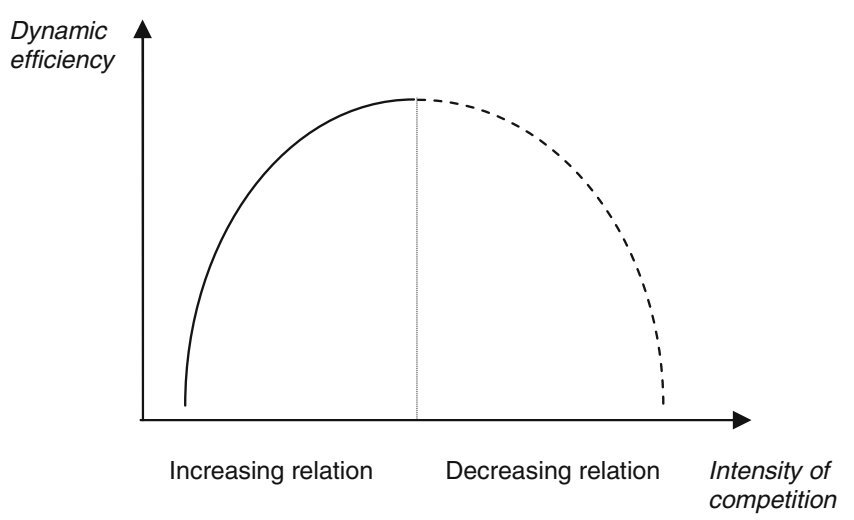

Fig. 2 Relationship between competition and dynamic efficiency 


\subsubsection{Incentives for tiering and horizontally differentiating networks}

The Internet as it is currently functioning can be seen as open, mainly responsible for data transmission, therefore provides equal opportunity to appearance of all kinds of applications, and is therefore not tuned for special types of data flow. Due to this characteristic, the Internet platforms are called "stupid" networks or as commodities.

By keeping the networks commoditized, network operators may only be able to charge modest mark-ups, thus eroding the profit margin, which is against their longterm interest. Contrarily, they may have incentives to "decommoditize" their infrastructure and operate them as smart networks where particular data packages are transmitted through the platforms differently on the basis of assigned priorities. ${ }^{27}$ Network owners can therefore attach prices to the priorities, engaging in different kinds of tiering practices (see earlier consumer- and access-tiering).

One of the root causes of the network neutrality discussion was the statement of Ed Whitacre, CEO of AT\&T when he openly expressed the will to discriminate. ${ }^{28}$ Since then other telecoms have given voice to similar opinions in the news (see Crawford 2007, and other examples ${ }^{29}$ ).

Besides these anecdotal sayings of leading market players about their intention to tier, theoretical evidences can also be found behind networks' incentive to differentiate themselves from each other. According to Farrell and Weiser $(2003)^{30}$, a network operator is interested in vertical control of the application market when it wants to be engaged in price discrimination. By setting different prices for a bundle of the platform and particular applications, it can customize its offer to the buyers, separating those consumers who are willing to pay more (inframarginal consumers) from those who would switch for a price increase (marginal consumers). In case of consumers as end-users, this situation can be translated to consumer-tiering, and while application providers act as end-users, this corresponds to access-tiering.

\footnotetext{
${ }^{27}$ D. Isenberg and D. Weinberger in an on-line article "The Paradox of the Best Network" from 2004, accessible at http://netparadox.com/.

28 'Now what [Google, MSN, Vonage and others] would like to do is use my pipes for free, but I ain't going to let them do that because we have spent this capital and we have to have a return on it. So there's going to have to be some mechanism for these people who use these pipes to pay for the portion they're using." R.O.Crockett, "Online Extra: At SBC, It's All about Scale and Scope," November 7, 2005, interview with Ed Whitacre, http://www.businessweek.com/@@n34h*IUQu7KtOwgA/magazine/content/ 05_45/b3958092.htm.

${ }^{29}$ V. Vittore, "Cable flying under net neutrality radar," Telephony Online, March 6, 2006, about cable companies, http://telephonyonline.com/mag/telecom_cable_flying_net/; D. Searcy and A. Schatz, "Phone Companies Set Off a Battle Over Internet Fees," Wall Street Journal, January 6, 2006, about Verizon, http://www.freepress.net/news/13218; BellSouth about net neutrality, April 3, 2006, http://slashdot.org/ article.pl?sid=06/03/06/003204; Joseph Waz, Keynote Remarks, Broadband Policy Summit, Washington, D.C., May 10, 2006 http://www.ncta.com/DocumentBinary.aspx?id=357; J. Sherman, "Expanded Alliance Makes BellSouth DSL Service Available to DirecTV Subs", February 14, 2006, about DSL-satellite deals, http://www.tvweek.com/news.cms?newsId=9390.

${ }^{30}$ Let us note that the authors explain their view about vertical leverage in a monopoly setup.

型 Springer
} 
Stennek (2007) also argues that network operators are interested in exclusive deals with application providers in the comparable applications market when the quality of services can be increased. ${ }^{31}$

Based on this argument, we assume that network operators intend to decommoditize their infrastructure by selling priorities and making exclusive deals at the same time.

\subsection{Benchmark case}

In the current situation of network neutrality, services and applications are provided in a non-discriminative manner. By buying Internet access, consumers can use or purchase all available services, applications and content (as it is illustrated in Fig. 1). In addition, they can develop applications themselves (not depicted in the figure). Therefore the market outcome is as if consumers are able to contract directly with application or service providers. In terms of variety and prices of services, it does not matter for consumers with which network operator they deal; it is as if the market is homogeneous at the networks level.

Note that the Internet's current structure has created many opportunities for startups to enter the services and applications market thus providing numerous valuable options for consumers. Firms such as eBay, Google and Yahoo have grown enormously and are now very prominent players. As we discussed in Section 3.1, we can observe application-level innovations and investments continuing to occur at the edges. Moreover, there is effective facilities-based competition between network operators, and we assume that there is no wasteful duplication of investments in networks. Therefore our starting point or benchmark situation seems to be characterized by relatively high static as well as high dynamic efficiency.

\subsection{Port blocking and quality degradation}

To dive into the potential practices that may harm network neutrality, let us first look at port blocking and quality degradation, as depicted in Fig. 3. We start with considering the incentives for blocking and quality degradation and their potential consequences in a competitive network market, then we assess whether network operators have incentives to continue to discriminate in this way in the long run and finally we derive policy implications.

Van Schewick (2007) provides an extensive argument about the existing incentives to block or degrade the quality of lanes, even in the case of a network duopoly. The network operator has an incentive to discriminate when it provides or sponsors a service that competes directly with the blocked site (e.g. fixed telephony vs. VoIP). The network operator has incentives to capture more revenues from its

\footnotetext{
${ }^{31}$ This kind of price discrimination can be observed in the cable television market, when different cable companies offer packages with different sets of television programs. The causes will be explained more detailed in Section 3.4.
} 


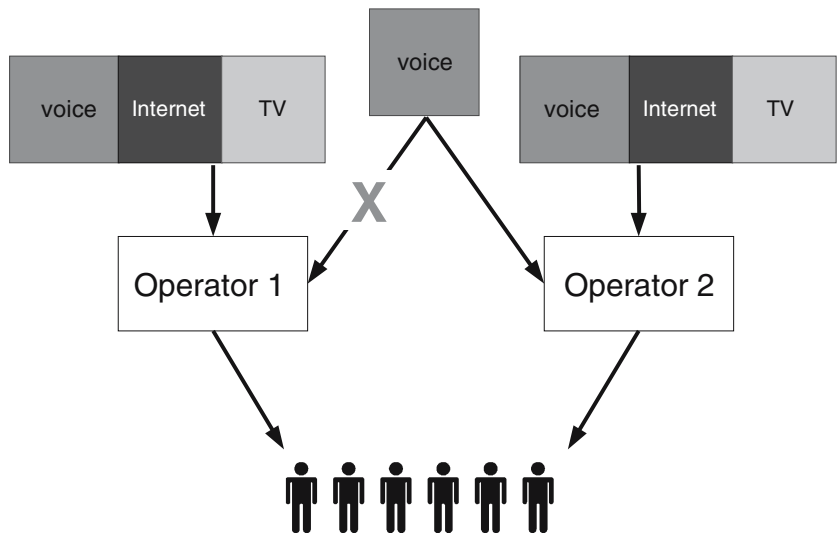

Fig. 3 Port blocking and quality degradation by operator 1

own end-user services ${ }^{32}$ and also more outside revenues, for instance from advertisements due to the two-sided nature of the Internet market. By blocking the competing service or degrading the quality of lanes used by that particular service, the network operator's customers will use its own service, resulting in a monopoly position over its customer basis and at the same time in a more stable market share. Due to the first effect, the network operator may increase its prices, and so its revenue captured in the market for services and applications. The second effect that is the stable market share and the relating positive network externalities ${ }^{33}$ help the firm to attract more advertisers, thus increasing its outside revenues.

In the absence of sufficient (facilities-based) competition, blocking and quality degradation can be seen as an effective anticompetitive practice, which typically reduces static and dynamic efficiency. Application developers may easily lose incentives to innovate and invest by the threat of being blocked, since they can drop out of the market without having the opportunity to recoup their investments. Blocking therefore decreases dynamic efficiency in applications and services markets. As for the networks level, the above mentioned sources may give enough incentives for network operators to invest, thus increasing dynamic efficiency. This effect can be illustrated as an upward shift of the inverted U-shaped curved (see in Fig. 4 with dashed line).

On the other hand, network operators may become "lazy monopolists" in the achieved market position - that is moving leftwards on the inverted U-shaped curveand cease to invest, resulting in decreased dynamic efficiency.

One may ask whether in case of sufficient facilities-based competition, a network operator is able to maintain blocking in the longer term. Indeed, customers can walk

\footnotetext{
${ }^{32}$ Sappington and Weisman (2005) and Mandy and Sappington (2004) present the incentives for increasing network costs and degrading application quality in a monopoly market with vertically integrated firm. Mandy and Sappington also show that quality degradation may lead to increasing profit if quality matters for consumers, but to decreasing demand, prices and profit if consumers make their decision according only to price.

${ }^{33}$ Positive network externalities exist when a consumer's utility increases with an increase in the total number of consumers using the same product or service.
} 


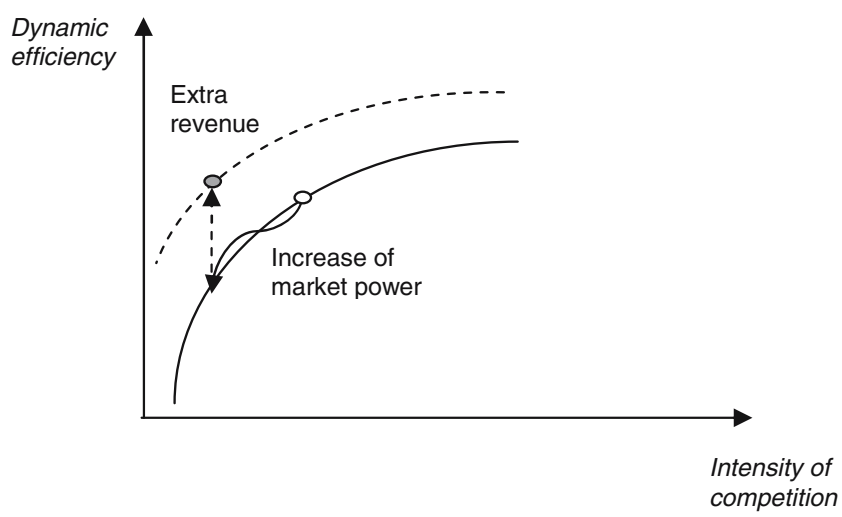

Fig. 4 Change in dynamic efficiency at the networks

away and choose another network if they are unhappy with the practice they face. If operator 1 blocks a service or degrades the quality of a line, then another network, say operator 2, may have an incentive not to block it since by providing more product variety or better quality, operator 2 can differentiate itself from operator 1 . As a result of differentiation, consumers are willing to pay more and if switching can be executed easily, operator 2 can increase its market share and its internal and external revenue. Therefore operator 1 may reconsider its blocking strategy.

If blocking and deliberate quality degradation occur, general competition law should be able to deal with it, as it can be seen in practice (e.g. Madison River case). However, the effectiveness of ex post intervention crucially depends on the effectiveness of monitoring, detection and punishment. Also, existing policy tools such as facilitating wholesale broadband access, securing easy switch for consumers or requiring interoperability may be sufficient to prevent these anticompetitive practices, under which a network operator cannot maintain its market power without losing too much of its market share. If above mentioned policy tools fail to prevent or handle these types of practices, then ex ante regulation may be desirable. In theory, the ultimate tool to eliminate them is vertical separation of network operators, that is, preventing them from competing with applications and services altogether.

\subsection{Access-tiering}

\subsubsection{The problem}

Addressing access-tiering is much less straightforward than the case of port blocking, as we will see below. Our starting point is the recognition that network operators are continuously facing the pressure that their networks are commoditized, selling capacity without any distinguishing functionality, and leaving them with eroded profit margins (see argument in Section 3.1). As we discussed there, to counteract this pressure, operators basically have two options: (1) to add "flavors" to their services, for instance through QoS-like functionality; and (2) to become gatekeepers that can extract rents from their customers, including application 
providers and end-users. Access-tiering provides the possibilities to do both. Therefore, the potential effects of access-tiering are twofold (depicted in Fig. 5):

1 Horizontal effect: due to making exclusive deals with application providers, network operators can distinguish themselves from one another. The result is horizontal differentiation, which allows operators to increase market power and hence mark-ups. ${ }^{34,35}$

2 Vertical effect: given the bargaining power arising from their "gatekeeper" role, network operators can try to extract surplus from application and service providers. Note that this power may be less if there is more intense competition between networks, as application and service providers then have more effective choice for a certain quality.

According to Fig. 5, access-tiering may reduce the intensity of competition between the networks, since the networks try to create market niches. This will work to the extent that application providers 1 and 2 (think e.g. of two IPTV service providers, one broadcasting sport programs, the other movies) are seen as differentiated offerings by consumers.

Arguably, this situation is more likely if there is a smaller number of competing networks. The reason is that with a larger number of competing networks, operators will have a harder time to differentiate themselves from one another. So, if there is a duopoly at the networks level-only two networks - then horizontal differentiation strategies may be rather effective.

In the following steps, we will discuss how access-tiering-by horizontal and vertical effects - may affect static and dynamic efficiency levels compared to the benchmark case.

\subsubsection{Effects on static and dynamic efficiency}

Access-tiering leads to horizontal differentiation (the horizontal effect), and therefore to a reduction in the intensity of competition. The networks market is subject to natural entry barriers such as economies of scale and sunk costs. Hence existing network operators are not immediately threatened by entry if they reduce the intensity of competition through horizontal differentiation. Therefore at the networks level it leads to higher prices for broadband access.

As horizontal differentiation takes place, consumer choice in the applications market is likely to be curtailed since consumers will face less variety of existing (or comparable) services. Originally they had access to all content on each network under the same conditions, whereas in the new situation the choice for a network may imply constrained access to some types of content. Another potential consequence of exclusive dealing is when an application provider starts to shift the burden of the cost of its deals to consumers, thus charging prices for previously

\footnotetext{
${ }^{34}$ Let us note that this problem has to be distinguished to the general horizontal differentiation where consumers have a priori preferences over a particular service or product (e.g. red cars versus black cars). The current type of differentiation is artificially generated by the network operators.

${ }^{35}$ As in a Hotelling model (see Tirole 1988).

型 Springer
} 
Networks become less close substitutes
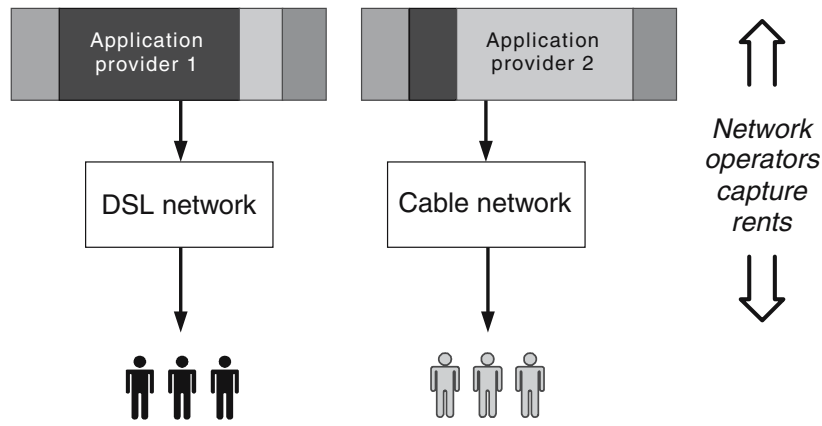

Fig. 5 Access-tiering leading to product differentiation and rent capturing

free services. However as participants of the network neutrality discussion claim, if the current subscriber-based business model of electronic communications market is replaced by an advertiser-based model, this later problem will be less likely to happen. Finally, not being able to engage in exclusive deals, start-ups may stay outside the market, or companies with small market share may either easily drop out or be forced to merge with larger application providers which leads to higher market concentration. By acquiring smaller firms larger companies can assure or even increase their market power which in case of paying applications and services might lead to higher prices on that market.

For all these reasons we claim that in the presence of access-tiering and exclusive deals, static efficiency will be reduced.

The effect on dynamic efficiency at the networks level, due to the horizontal and vertical effects, is not clear cut. As we assumed in Section 3.1, the relationship between competition and dynamic efficiency is increasing (see Fig. 2), and this figure can be used to illustrate the effects of access-tiering on long-run welfare. The horizontal effect (differentiation) gives the networks more market power. Hence, horizontal differentiation can be illustrated as a downward move in the inverse U-shaped curve, thus resulting in lower dynamic efficiency (illustrated in Fig. 4).

By capturing rents (the vertical effect), networks make more profits which could be used for additional investments. Note also that due to mandatory unbundling, a fringe of DSL entrants without networks imposes intense competition on network operators; product differentiation might then be useful to restore the returns on investment for network operators. ${ }^{36}$ The vertical effect can be translated as the inverted U-shaped curve shifts upwards, meaning increasing dynamic efficiency at a certain level of competition. Whether the new market outcome, which is depicted by the grey dot in Fig. 4, reflects to higher or lower overall effect on dynamic efficiency at the networks level depends on how these two opposite effects compare to each other. Policy makers will have to assess the magnitude of these effects.

The effect on dynamic efficiency at the services and applications level can be separated into on the one hand, new innovations that have originated from end-users at the edges, and on the other hand, improvements and imitations of already existing services, possibly carried out by network operators.

\footnotetext{
${ }^{36}$ See Ford et al. (2006).
} 
According to our first assumption in Section 3.1, access-tiering is undesirable for dynamic efficiency since developers of the radically new applications - at the edges will most likely not be able to enter exclusive deals for receiving priorities. At least, this may be the case when the commercial value of such innovations has not yet been established. Having degraded priority, they face higher risk of achieving too little critical mass in their customer base to successfully enter the market. The lack of innovation at the edges might be more pronounced in case of high quality applications and services, such as voice and video. As we claimed in assumption 1, innovation at the edges has a preference since it displays higher share within overall innovations at the applications level and carries higher value for dynamic efficiency. If there is a lack of radically new innovations, dynamic efficiency will be strongly harmed.

To provide a complete view on how access-tiering affects dynamic efficiency, we also have to consider the adoption of existing innovations (that were originally developed by end-users and small start-ups) by big firms. This market shows a more competitive characteristic with the participation of bigger application providers and network owners. In the market of these services, companies may enter exclusive deals with network operators, buying priorities for their services. Those application and service providers which get priorities may gain a larger and, because of product differentiation, more stable market share, and as a consequence higher external revenues. According to Stennek (2007), under specific conditions these external revenues may give application providers stronger incentives to invest in higher quality of services. He argues that with higher quality applications, providers are able to increase their market share which makes their products more attractive to advertisers. As it can already be seen, advertising revenues are becoming more relevant leading to the change of business models in the electronic communications market.

Let us make some additional comments, relating to the complementary relation between networks and applications. Innovation in applications and services increases the demand for Internet access and vice versa. Therefore in case of separate providers, not all the positive effects arising from investments can be obtained by the investor. As a result of these externalities, the firms in both levels will have fewer incentives to invest than the social optimal level. ${ }^{37}$ When investments at both the networks and applications level are brought about by the same (vertically integrated) firm, these externalities can be internalized leading to the social optimal level of investment and therefore increasing the incentives of network operators to invest.

\subsubsection{Scenarios and the level of intervention}

From the discussion above, we can generally conclude that access-tiering reduces static efficiency. We will now consider three scenarios according to whether the overall dynamic efficiency - in the applications and networks levels - gets higher $(-)$ or lower $(+)$ as a result of access-tiering, or the overall effect is negligible (0). See Table 1. In this table, we "calculate" overall welfare by aggregating static and dynamic efficiency under the assumption that dynamic efficiency (which has a long time horizon) gets a substantially larger weight than static efficiency.

\footnotetext{
${ }^{37}$ See van Schewick (2007) p. 388-389 and Farrell and Weiser (2003).

型 Springer
} 
Table 1 The aggregate welfare effects of access-tiering, decomposed into static and dynamic welfare

\begin{tabular}{|c|c|c|c|}
\hline & \multicolumn{3}{|c|}{ Effect of access-tiering on dynamic efficiency } \\
\hline & $(+)$ & (0) & $(-)$ \\
\hline & Scenario 1 & Scenario 2 & Scenario 3 \\
\hline $\begin{array}{l}\text { Effect of access- } \\
\text { tiering on static } \\
\text { efficiency }\end{array}$ & $\begin{array}{l}\text { Access-tiering is not } \\
\text { problematic (overall } \\
\text { effect: }+ \text { ) }\end{array}$ & $\begin{array}{l}\text { Access-tiering is } \\
\text { problematic (overall } \\
\text { effect: - but small) }\end{array}$ & $\begin{array}{l}\text { Access-tiering is strongly } \\
\text { undesirable (overall effect: - } \\
\text { and large) }\end{array}$ \\
\hline
\end{tabular}

In scenario 1, although static efficiency may be reduced as consumers' choices are reduced, increased market power for networks is assumed to have a positive effect on dynamic efficiency. Overall, policy makers need not worry about accesstiering, as the short-term negative effects are likely to be small compared to the longterm positive effect, and therefore they can use a "hands-off" policy. Nevertheless the regulator should remain alert that as a result of exclusive dealings, the reduction of variety and transparency should not become too problematic.

In scenario 2, the overall effect of access-tiering on long-term welfare is negligible. Nevertheless static efficiency gets lower, thus decreasing short-term welfare. Therefore the regulator may opt for using policy tools which spur the competition at the networks level (e.g. by stimulating facilities-based competition, or possibly mandating network unbundling). Then network operators have less long term incentives to discriminate unduly without losing their market shares.

In scenario 3, static efficiency is reduced and increased market power for networks is assumed to have a negative effect on dynamic efficiency. In this scenario, policy makers should try to prevent access-tiering, as it substantially reduces welfare. Interventions may range from specific access-tiering regulation (e.g. requiring non-discriminating offers for a certain priority, interoperability or minimal quality of service) to imposing network neutrality. Of course, the cost of such interventions, such as the cost of regulation and the risk of regulatory failure, has to be assessed before one can decide on the optimal type of intervention.

According to Wallsten (2006), not many empirical studies have shown how a regulatory intervention achieved its goal. The literature is mainly relating to mandated unbundling which we will cover in the following chapter. Other government policies which mainly aimed at helping connect more people to the Internet were more successful if they have subsidized public places such as schools or libraries, or encouraged investments in rural areas.

Those regulatory tools which require special standards to increase the universality and the openness of the Internet so far have contributed to the dynamic growth of the Internet including investments in both levels (see Berners-Lee 2007). The scope of these tools can be extended in a straightforward manner by requirements on interoperability or minimal quality of services.

Finally, as we have already mentioned in the introduction imposing rules to maintain network neutrality is likely to facilitate innovations at the edges, but it might decrease incentives to invest in and upgrade networks. At this stage, it is hard to assess whether the benefits outweighs the costs. 
3.5 Can more intensive competition between networks mitigate the negative consequences of discriminative practices?

To answer this question, we draw up two potential solutions: first we assume that service-based competition intensified by regulatory intervention such as mandated access, takes place in the networks level; in the second case we assume a marketbased response where one of the application providers has an incentive to build up its own network and therefore intensify facilities-based competition.

\subsubsection{Access-tiering and regulating access to networks}

In addition to interventions aiming at restoring a degree of network neutrality, it may also be desirable to spur competition between networks. This is particularly so if competition between networks is reduced to the detriment of short-term interest of consumers. Then low static efficiency can be increased by approaching more intense competition using existing regulatory tools as mandated access to networks. Accordingly, new competition is introduced, which may alleviate the softening in competition that was caused by product differentiation (see Fig. 6).

Of course, regulators should prevent that competition becomes too intense, which could easily revert the relationship between competition and dynamic efficiency (right-hand side of the U-shaped curve in Fig. 2).

In the context of access regulation, it is interesting to comment on the situation for instance in The Netherlands, where the DSL network operator, because of its dominant position, faces access obligations. The various regional cable operators, based on the EU regulation do not have to provide access to entrants. As a result, besides that there is a duopoly in networks in each region, the competitive landscape is characterized by a variety of DSL entrants without their own networks. Their primary service is broadband Internet access, but some also offer digital television or VoIP telephony. Without the fringe of DSL entrants, there would just be a duopoly, so that, as was observed above, access-tiering can be expected to be an effective means of horizontal product differentiation, leading to softening of competition and reduced transparency for end-users. The overall effect would be a decrease in static efficiency. Perhaps the presence of DSL entrants counteracts this welfare reduction: consumers have more choice and alternatives, if they do not like the offerings based on priorities and discrimination offered by the network operators. Thus, in the light of the potentially negative effects of access-tiering on static efficiency, it may be worthwhile to stick to regulated access. ${ }^{38}$

However some empirical and case studies showed that mandated access has not necessarily affected broadband penetration and investment decisions in a positive way. Hausman and Sidak (2005), in their empirical research about the USA, the UK, New Zealand, Canada and Germany, show that companies with unbundling requirement expected lower returns to investments. Moreover, entrants have not corresponded to the 'stepping-stone' theory meant to intensify service-based competition first and by that in the next step give incentives to invest in their own

\footnotetext{
${ }^{38}$ In this discussion, we abstract from the asymmetry of access regulation between the DSL incumbent and the cable operators. We also abstract from the effect of access regulation on dynamic efficiency.

Springer
} 


\section{$\longrightarrow$ Networks become closer substitutes}

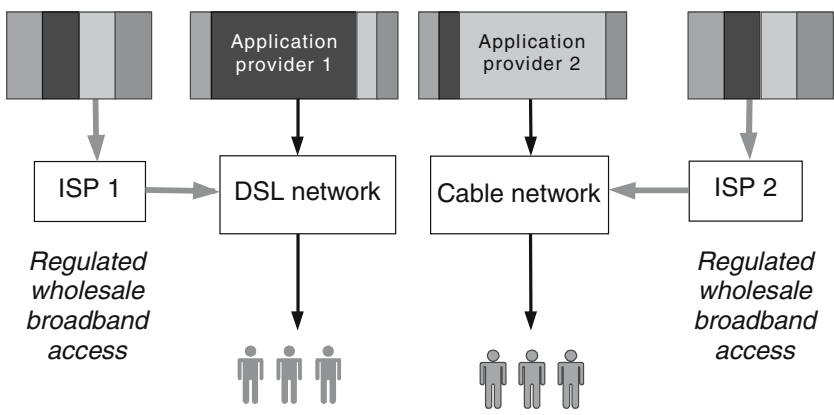

Fig. 6 Access regulation aiming at increasing service-based competition

network. As Denni and Gruber (2005) found in their analysis about the DSL market in the USA, service-based competition has initially increased broadband adoption, however this effect disappeared over time.

Wallsten (2006), analyzing different types of unbundling (local loop or subloop unbundling, and on-site collocation) derives similar conclusions, and though collocation not necessarily decreases broadband penetration, it does so if the collocation charge is regulated. On the other hand, lack of regulation (as e.g. shown in Crandall (2005) examining the broadband market in Korea and Canada) or ended regulations (e.g. Hazlett (2006) about DSL market in the USA) increased investments also in roll-outs.

Theoretical papers also discuss the effect of regulation on market outcomes. Let us emphasize one relating to mandated access. Farrell and Weiser (2003) claim that regulated access fee may give incentives for a network operator to make further exclusive deals with application providers, since it can compensate for the fact that its infrastructure is used at a price lower than the profit maximizing level.

To conclude, although mandated access may intensify service-based competition thus increasing static efficiency, the regulator has to keep in mind that it may also lead to lack of incentives to invest at the networks level, which decreases dynamic efficiency.

\subsubsection{Application providers building their own networks}

In response to port blocking, quality degradation and access-tiering, applications and service providers may want to reduce their dependence on network operators. Perhaps the most effective way to do so for a service operator is to roll out its own network (see Fig. 7). ${ }^{39}$

\footnotetext{
${ }^{39}$ For instance in September, 2005, Google announced to build up a free WiFi local network in San Francisco; see: http:/gigaom.com/2005/09/30/google-confirms-san-francisco-wifi-plans/. As a first step, it has installed and been managing a municipal WiFi network in its hometown of Mountain View, California since August 2006. In the meantime, Google agreed with the DSL entrant Earthlink to install the network in SF, but the realization is obscured by the discussion in the municipalities whether a privately owned or a city-owned network is the proper solution (see http://www.localtechwire.com/business/local_tech_wire/ opinion/story/1210597/). As a reaction, another company, the Meraki Networks decided to establish its own WiFi network in the same region (see http://www.wirelessweek.com/article/CA6421866.html).
} 


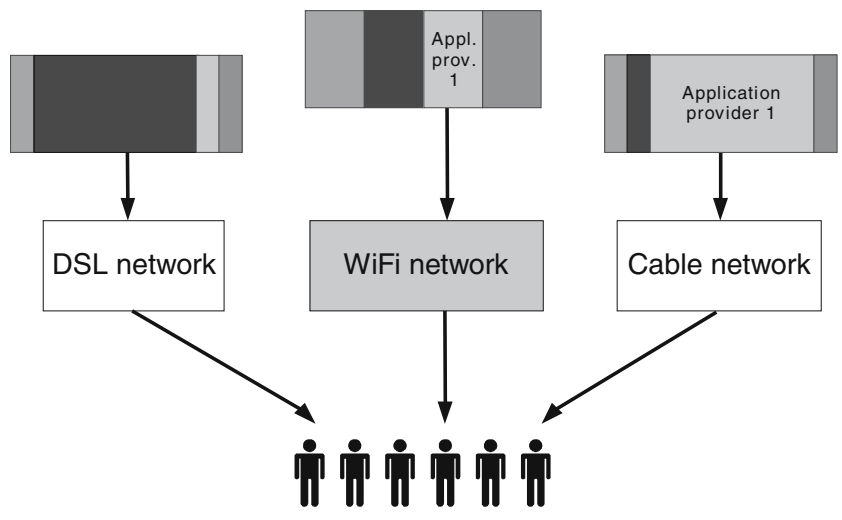

Fig. 7 Service provider building its own network

If this happens, it is the market that finds a solution to practices that undermine network neutrality. As a result, facilities-based competition will become more intense, while the variety of services for consumers will remain intact. However, because of network duplication, static efficiency may be reduced. Overall, it is therefore uncertain whether such a market-based response is better for welfare than policy intervention.

\section{Conclusion and preliminary policy recommendations}

Although end-users buy access to the Internet and get indirect access to applications and services, the Internet currently functions in a more or less neutral way, as if consumers contract directly with application and service providers, without the interference of network operators. However, emerging technologies enable network providers to attach priorities to, and discriminate between, services and applications, possibly dependent on the value that end-users derive from them. By doing so, they may distinguish themselves from other networks (horizontal differentiation), and also capture rents from application and service providers. An important question is whether, given that there is facilities-based competition at the level of networks, such discriminatory practices may harm welfare.

In this paper, we considered the discriminating practices known as port blocking or deliberate quality degradation, and access-tiering. If facilities-based competition is sufficiently intense, port blockers will lose customers quickly to other networks, and there will be sufficient discipline. If there is a lack of competition at the networks level, port blocking and quality degradation are typically bad for welfare, and should be discouraged by antitrust policy. If facilities-based competition is sufficient, a network operator may back out of using blocking because of the potential loss in its market share. Nonetheless, if anticompetitive practices take place and the ex post intervention is not effective, for instance because such practices are difficult to detect, ex ante regulation may be desirable, say through technical requirements on network traffic. Further research is necessary to assess whether policy makers should worry about port blocking and quality degradation. In any case, it does not seem a 
safe strategy to bet on the good intentions of network operators or on the lack of technologies to implement such practices.

Access-tiering is more difficult to assess from a welfare perspective. First of all, it can be expected to soften competition between networks and to reduce variety and transparency for consumers, both of which are bad for static efficiency. In addition, it can increase network operators' bargaining power with regard to developers of applications and services. The increase in market power that results from these horizontal and vertical effects, might improve the incentives of networks to invest and innovate. If that is the case, a hands-off approach can suffice. On the other hand, if the increase in network operators' market power which is due to access-tiering reduces their incentives to invest and innovate, and also withhold the development on innovations at the edges, policy makers should step in. Similarly, if long-term welfare effects are negligible, access-tiering will yet harm short-term welfare, calling for policy intervention.

A variety of policy tools can be imagined ranging from "hands-off" policy (let the market take care of the situation), through a minimal type of intervention (interoperability or minimal quality of services), to more specific interventions (for instance regulation aiming specifically at access-tiering, or more drastically, imposing network neutrality through regulation). Our paper suggests that doingnothing policy might be risky because of the potential welfare loss. On the other hand, specific intervention may create heavy burden on market players, and since at this stage of the research the real welfare loss cannot be exactly assessed, the risk of regulatory failure may be large. An intermediary type of solution (minimal intervention), could be relying on interoperability requirements, in which, compared to the option of doing nothing, the operators face minimal obligations, while applications and services providers do not have to carry the burden of proof if things go wrong from their perspective. This solution includes little regulatory costs, does not require additional information, and bears little risk of regulatory failure or distorting market incentives. Despite some experience with interoperability in telephony, more analysis is needed to assess how effective and efficient interoperability can be.

If there is sufficient competition between networks, then access-tiering, assuming it reduces dynamic efficiency, may be somewhat less harmful, as consumers can switch to other networks. However, it is unclear exactly when there is sufficient competition between networks. With only two networks (e.g. DSL and cable), the effect of access-tiering may simply be that competition is softened while consumers have a harder time in matching their preferences to the portfolios offered by the networks. The larger the number of networks, the less this is likely to happen. Thus, if alternative networks, such as FTTH, UMTS and WiFi local networks, offer sufficient outside possibilities for a large enough subset of consumers, the welfare harms need not be substantial. The same can be said if, because of regulated access, there is a fringe of DSL entrants (other ISPs) that impose competitive discipline on the network operators. On the other hand, if alternative networks do not play a significant role and if there are no DSL entrants, so that effectively there are a very small number of network operators, then access-tiering may hurt both consumers and the developers of applications and services. 
Let us finally relate the remarks on competing networks to our example of the situation in the Netherlands, which has the second largest broadband penetration in the world. Both the incumbent telecoms operator and various regional cable operators are now able to offer triple play bundles, not to mention regulation of local loop unbundling allowing for DSL entrants who use the incumbent's network. Given that alternative networks such as FTTH do not yet play a significant role, within network owners there is a duopoly situation and in the networks level as a whole there are a few more market players. Access-tiering can then be expected to lead to horizontal differentiation between networks, and hence to softening of competition. In addition, it will help networks to capture rents from developers of applications and services. Provided that content providers rather than networks that drive innovation, along the lines of the arguments set out in this paper, access-tiering may call for policy intervention. In particular, under the hypothesis that access-tiering reduces dynamic efficiency, the number of competing networks in The Netherlands may simply be too small to alleviate the negative welfare effect of access-tiering. Furthermore, we argued that the presence of DSL entrants may counteract the reduction of static welfare caused by access-tiering, as it gives consumers more choices and alternatives, if they do not like the offerings based on priorities and discrimination offered by the network operators. However, we have not addressed whether the presence of such a competitive fringe can also alleviate the reduction in dynamic efficiency.

To conclude, let us mention that at this stage, we aimed to raise the most important insights relating to discriminating practices in the Internet and derive some preliminary conclusions and policy recommendations. However, the analysis should be deepened by using economic models that can lay bare the effects of access-tiering on the incentives of network operators and content providers to innovate and to invest.

Acknowledgment We are grateful to the anonymous referee and the editors of this issue for their advice and comments. We also wish to thank Rudolf van der Berg (DGET), Marco Haan (University of Groningen), Pierre Larouche (TILEC), Hans Kwakkenbos (DGET), Jens Prüfer (TILEC), Gregory Sidak (Georgetown University Law Center), Leonard Thijssen (DGET), participants of an ENCORE workshop at DGET, and participants at a TILEC workshop for helpful comments and discussions.

\section{References}

Aghion P, Bloom N, Blundell R, Griffith R, Howitt P (2005) Competition and innovation: an inverted-U relationship. Q J Econ 120(2):701-728

Anderson C (2004) The long tail. WIRED, Issue 12.10. Accessible at http://www.wired.com/wired/ archive/12.10/tail.html

Benkler Y (2006) The wealth of networks: how social production transforms markets and freedom. Yale University Press, New Haven

Bennett M, de Bijl PWJ, Canoy M (2001) Future policy in telecommunications: an analytical framework CPB document no. 005, CPB Netherlands Bureau for Economic Policy Research

Berners-Lee T (2007) Testimony before the US House of Representatives Committee on energy and commerce subcommittee on telecommunications and the internet hearing on the digital future of the US: Part I-the future of the world wide web March 1, 2007. Available at http://energycommerce. house.gov/cmte_mtgs/110-ti_hrg.030107.WorldWideWeb.shtml 
Crandall RW (2005) Competition and chaos: U.S. Telecommunications since the 1996 telecommunications act. Brookings Institution Press, Washington

Crawford SP (2007) The Internet and the project of communications law. Mimeo, Cardozo School of Law. Accessible at http://ssrn.com/abstract $=962594$

de Bijl PWJ (2004) Competition, innovation and future-proof policy. TILEC Paper, Tilburg University. Available at http://www.tilburguniversity.nl/tilec/publications/report/policy.pdf

Bijl PWJ de, Peitz M (2006) Broadband access in Europe: challenges for policy and regulation. CESifo DICE Report, 3/2006

Denni M, Gruber H (2005) The diffusion of broadband telecommunications: the role of competition. Mimeo, European Investment Bank and University of Rome. Accessible at http://papers.ssrn.com/ sol3/papers.cfm?abstract_id=829504

Distaso W, Lupi P, Manenti FM (2006) Platform competition and broadband uptake: theory and empirical evidence from the European Union. Info Econ Policy 18:87-106

Farrell J, Weiser PJ (2003) Modularity, vertical integration, and open access policies: towards a convergence of antitrust and regulation in the Internet age. Harv J Law Technol 17(1):85-134

Ford GS, Koutsky TM, Spiwak LJ (2006) Network neutrality and industry structure. Phoenix Center Policy Paper, No. 24

Frieden R (2006) Network neutrality or bias? Handicapping the odds for a tiered and branded Internet. Mimeo, Pennsylvania State University. Accessible at http://papers.ssrn.com/sol3/papers.cfm?abstract_id=893649

Hahn RW, Wallsten S (2006) The economics of net neutrality. The Economists' Voice 3/6. Accessible at http://www.bepress.com/ev/vol3/iss6/art8

Hausman J, Sidak G (2005) Did mandatory unbundling achieve its purpose? Empirical evidence from five countries. J Compet Law Econ 1/1:173-245

Hazlett T (2006) Rivalrous telecommunications networks with and without mandatory sharing. Fed Commun Law J 58/3:477-510

Isenberg D (1997) Rise of the stupid network. Accessible at http://www.isen.com

Larouche P (2000) Competition law and regulation in European telecommunications. Hart, Oxford

Lessig L (2006) Testimony before the Senate Committee on Commerce, science and transportation hearing on network neutrality February 7, 2006. Accessible at http://commerce.senate.gov/hearings/witnesslist. cfm?id $=1705$

Litan RE, Singer HJ (2007) Unintended consequences of net neutrality regulation. J Telecommun High Technol Law 5(3):533-572

Mandy DM, Sappington DEM (2004) Incentives for sabotage in vertically-related industries. Department of Economics, University of Missouri Working Papers No. 0404

Markey E (2006) Strike Section 201 of the bill and insert the following: Section 201. Network Neutrality, Outvoted amendment to H.R.5252 at US House. Accessible at http://www.rules.house.gov/109_2nd/ specialrules2nd109/hr5252/109hr5252_markey20.pdf

Odlyzko A (2004) Telecom dogmas and spectrum allocation. Mimeo, Digital Technology Center, University of Minnesota. Accessible at http://www.dtc.umn.edu/ odlyzko/doc/telecom.dogmas.spectrum.pdf

Powell MK (2004) Remarks at the silicon flatirons symposium on 'the digital broadband migration: toward a regulatory regime for the Internet age', University of Colorado School of Law Boulder, Colorado February 8, 2004. Accessible at http://www.cdt.org/speech/net-neutrality/20040208powell.pdf

Prüfer J, Jahn E (2007) Dark clouds over the Internet? Telecommun Policy 31(3-4):144-154

Sappington DEM, Weisman DL (2005) Self-sabotage. J Regul Econ 27(2):155-175

Shy O (2002) The economics of network industries. Cambridge University Press, Cambridge

Sidak G (2006) A consumer-welfare approach to network neutrality regulation of the Internet. J Compet Law Econ 2/3:349-474

Stennek J (2007) Exclusively quality-why exclusive distribution may benefit the TV viewers. CEPR Discussion Paper No. 6072

Tirole J (1988) The theory of industrial organization. MIT, Cambridge

van der Berg R (2006) Netwerkneutraliteit als Reguleringsprincipe. Verkennende Studie in het kader van het project Review New Regulatory Framework, DGET/CSI (Ministerie van Economische Zaken), Version 0.9.1, March 5

van Schewick B (2007) Towards an economic framework for network neutrality regulation. J Telecommun High Technol Law 5:329-392

von Hippel E (2005) Democratizing innovation. MIT, Cambridge, MA

Wallsten S (2006) Broadband and unbundling regulations in OECD Countries, AEI-brookings joint center for regulatory studies, Working Paper No. 06-16 
Waverman L (2006) Comments on network neutrality. J Compet Law Econ 2/3:475-477

Wu T (2005) Network neutrality, broadband discrimination. J Telecommun High Technol Law 2:141-178

Wu T (2006) Intellectual property, innovations, and decentralized decisions. Va Law Rev 92:101-127

Yoo C (2005) Beyond network neutrality. Vanderbilt University Law School Public Law \&amp; Legal Theory, Working Paper 05-20. Law \&amp; Economics Working Paper 05-16 